\title{
COMPARAÇÃO ENTRE A FIXAÇÃO DE COMPLEMENTO EM PLA- CA, A HEMOAGLUTINAÇÃO E Ã PROVA DE AGLUTINAÇÃO COM LÁTEX NO DIAGNOSTICO SOROLÓGICO DA DOENÇA DE CHA- GAS NA ZONA DO RIO GRANDE DO SUL
}

\author{
Giovanni Barutfa * e Alcino Alcantara Filho***
}

\begin{abstract}
Com a finalidade de avaliar o emprego do Antígeno Látex na triagem de pacientes portadores de infecção chagásica o mesmo foi comparado com a Fixação de Complemento em placa e com a Hemoaglutinação, em 3 grupos de soros:
\end{abstract}

a) 920 soros procelientes de inquérito epidemiológicos;

b) 131 soros procedentes de pacientes hospitalizados;

c) 90 soros procedentes de pacientes hospitalizados e familiares;

Os resultados mostraram baixos indices de co-positividade nos três grupos, evidenciando assim escassa sensibilidade por parte do antigeno Látex. Também a comparação entre a Hemoaglutinação e o Antigeno Látex, realizada nos 90 soros do grupo c evidenciou baixo indice de co-positividade.

A conclusão dos Autores é que o Antigeno Látex, pela sua escassa sensibilidade, $e$ conseqüente porcentagem de soros falsos negativos, não encontra indicaçăo na triagem sorológica em inquérito epidemiológicos, e na triagem de pacientes hospitalizados.

\section{INTRODUÇÃO}

Relatamos em trabalho anterior os resultados obtidos comparando a Aglutinação com Látex e a Imunofluorescência no diagnóstico sorológico da Doença de Chagas em 142 amostras de soros (3). Animados pelos bons índice de concordância entre as duas técnicas $(97,9 \%)$, resolvemos continuar nossos estudos estendendo a comparação à reação de Fixação de Complemento e à Hemoaglutinação. Era nossa intenção averiguar a validade ou não do uso do Látex como reação de extrema praticidade e rapidez tanto na triagem soro- lógica em inquéritos de campo em zona endêmica, quanto na triagem de doadores em bancos de sangue e de pacientes hospitalizados procedentes de zonas endêmicas.

Um estímulo à execução do trabalho nos veio das opiniões discordantes dos $\mathrm{Au}$ tores com referência à validade da prova de Látex como método de diagnóstico da Doença de Chagas. De fato, se temos por um lado opinióes favoráveis como a de Pellegrino e Katz (6) temos pelo outro sérias reservas como as de Knierim e Cols. (5), Camargo e Shimizu (4) e aquelas movidas pelos participantes do 19 Simpósio Internacional sobre a Doença de Chagas

Trabalho realizado pela Cadeira de Doenças Infecciosas e Parasitárias do Curso de Medicina da Universidade Católica de Pelotas, Rlo Grande do Sul.

* Professor Titular de Doenças Infecclosas e Parasitárias.

** Professor Adjunto do Departamento de Patologla e Medicina Legal.

Recebido para publicação em 14-3-1975. 
(4). Encontramos ainda algumas disparidades entre os resultados obtidos pelos 8 (oito) laboratórios que ensaiaram o Látex em paralelo com a Fixação de Complemento, e, alguns, também com Imonufluorescência (7).

\section{MATERIAL E MÉTODOS}

O nosso material compreende:

a) 902 soros colhidos em zonas rurais e urbanas dos Municípios de Pelotas (362), Bagé (46), Caçapava do Sul (111) e Dom Pedrito (383). Os referidos municípios são todos situados na Zona Sul do Rio Grande do Sul e têm em seu território áreas de endemia chagásica.

b) 131 soros procedentes de pacientes hospitalizados no Departamento de Clínica Médica do Curso de Medicina da Universidade Católica de Pelotas (Santa Casa de Misericórdia de Pelotas).

c) 90 soros procedentes de pacientes hospitalizados e familiares.

O reagente Chagas Látex, preparado pelo Laboratório Behringwerke AG (Marburg - Lahn - Alemanha Ocidental), é constituído de uma suspensão de partículas de polistireno às quais é absorvido um antigeno purificado de Trypanosoma cruzi.

o antígeno Látex usacio nos soros do grupo a) pertencia ao lote no 27.770 ; nos soros do grupo b) e c) foi usado antígeno Látex pertencente ao lote no $48 \mathrm{~F}$. O antigeno foi conservado em geladeira e empregado antes da data de vencimento.

A reação é executada misturando uma gota de soro não diluído e sem inativação com uma gota de antígeno sobre uma placa de plástico enegrecida; agita-se manualmente a placa durante 5 minutos; faz-se a leitura macroscópica com luz intensa. Dependendo da intensidade da aglutinação e do tamanho dos grumos, a aglutinação se quantifica de uma a quatro cruzes.

Para a Fixação de Complemento foi utilizada a técnica em placa segundo Almeida (1). Numa primeira triagem foi empre gado um antígeno tríplice (antígeno meetílico de Trypanosoma cruzi preparado se- gundo a técnica de Baracchini e Cols (2); antígeno aquoso de Brucella abortus, antígeno Cardiolipina Sycco). Todos os soros positivos ao antígeno tríplice foram testados com os três antígenos separadamente.

A reação de Hemoaglutinação foi executada em placas plásticas com cavidades em $\mathrm{V}$, utilizando reagente de Ḣemoaglutinação liofilizado, gentilmente fornecido pelo $\mathrm{dr}$. Mário E. Camargo, do Laboratório de Imunologia do Instituto de Medicina Tropical de Sāo Paulo.

\section{RESULTADOS}

a) 902 soros procedentes do inquérito de campo:

Foram utilizados o antígeno Látex e a reação de Fixação de Complemento em placa segundo Almeida. Os resultados estão no Quadro 1.

b) 131 soros procedentes de pacientes hospitalizados:

Fixação de Complemento em placa segundo Almeida. Os resultados estão no Quadro 2.

c) 90 soros de pacientes hospitalizados $\mathrm{e}$ familiares. Nestes soros a reação do Látex foi comparada com a Fixação de Complemento em placa (Quadro 3) e com hemoaglutinação (Quadro 5)

\section{COMENTÁRIOS}

Como se deduz dos quadros apresentados, a sensibilidade do Antígeno Látex, tomando como referência a reação de Fixação de Complemento em placa e a Hemoaglutinação resultou baixa em todos os grupos de soros. A especialidade pelo contrário pareceu boa.

Com o emprego do Látex nos nossos soros, foram mais comuns e freqüentes os resultados falsamente negativos (sensibilidade) que não os resultados falsamente positivos (especificidade).

Como podemos deduzir do Quadro 1, a porcentagem de soros positivos com a reação do Látex foi de $13,63 \%$ e com a reação de Fixação de Complemento de $14,85 \%$. A pequena diferença de $1,22 \%$ poderia não ser prejudicial para a avaliação da situação da endemia num inquérito de campo. A existência porém de um número relati- 
QUADRO I

RESULTADOS COMPARATIVOS DA REAÇÃO DE FIXAÇÃO DE COMPLEMENTO EM FLACA E DA REAÇÃO DO LÁTEX EM 902 SOROS PROCEDENTES DE INQUÉRITO EM ZONA ENDÊMICA

\begin{tabular}{|c|c|c|c|}
\hline \multirow{2}{*}{ FIXAÇÃO DE COMPLEMENTO } & \multicolumn{2}{|c|}{ LÂTEX } & \multirow{2}{*}{ TOTAL } \\
\hline & REAGENTE & NÃO REAGENTE & \\
\hline REAGENTE & 82 & 52 & 134 \\
\hline NÃO REAGENTE & 41 & 727 & 768 \\
\hline TOTAL & 123 & 779 & 902 \\
\hline
\end{tabular}

Houve concordância de resultados em 809 soros $(89,68 \%)$.

Indice de Co-positividade $=$ (sensibilidade)

$$
\frac{\text { LATEX }}{F C}=\frac{82}{134}=0,6119
$$

Indice de Co-negatividade $=$ (especificidade)

$$
\frac{727}{768}=0,9466
$$

Os índices indicam baixa sensibilidade do teste do Látex em relação a Fixação de Complemento, apesar de elevada especificidade. 


\section{QUADRO 2}

\section{RESULTADOS COMPARATIVOS DA REAÇAO DE FIXAÇAO DE COMPLEMENTO EM PLACA E DA REAÇĀO DO LÁTEX EM 131 SOROS DE PACIENTES HOSPITALIZADOS}

\begin{tabular}{l|c|c|c}
\hline & \multicolumn{2}{|c|}{ LATEX } & \multirow{2}{*}{ TOTAL } \\
FIXAÇAO DE COMPLEMENTO & REAGENTE & $\begin{array}{c}\text { NAO REA- } \\
\text { GENTE }\end{array}$ & \\
\cline { 2 - 5 } REAGENTE & 47 & 14 & 61 \\
\hline NAO REAGENTE & 15 & 55 & 70 \\
\hline TOTAL & 62 & 69 & 131 \\
\hline
\end{tabular}

Houve concordância de resultados em 102 soros $(77,8 \%)$.

$O$ indice de co-positividade $\frac{47}{61}=0,7704$

mostra também aqui baixa sensibilidade.

\section{QUADRO 3}

COMPARAÇĀO ENTRE A REAÇAO DE FIXAÇĀO DE COMPLEMENTOS EM PLACA E A REAÇÃO DO LATEX EM 90 SOROS

\begin{tabular}{|c|c|c|c|}
\hline \multirow{2}{*}{ FIXAÇÃO DE COMPLEMENTO } & \multicolumn{2}{|c|}{ LATEX. } & \multirow{2}{*}{ TOTAL } \\
\hline & REAGENTE & $\begin{array}{c}\text { NAO REA- } \\
\text { GENTE }\end{array}$ & \\
\hline REAGENTE & 33 & 31 & 46 \\
\hline NÃO REAGENTE & 7 & 37 & 44 \\
\hline TOTAL & 40 & 50 & 90 \\
\hline
\end{tabular}

Houve concordância de resultados em 70 soros $(77,77 \%)$

0 indice de Co-positividade foi $=$
0,7174 , evidenciando mais uma vez a baixa sensibilidade do Látex.

0 índice de Co-negatividade foi $=$ 
0,8409 evidenciando uma especificidade um pouco melhor.
Reunimos no Quadro 4 os resultados globais da Comparação entre Fixação de Complemento e Látex.

\section{QUADRO 4}

COMPARAÇAOO ENTRE FIXAÇAO DE COMPLEMENTO E LATTEX NO TOTAL DE 1123 SOROS CONSIDERADOS NO PRESENTE TRABALHO

\begin{tabular}{l|c|c|c}
\hline & \multicolumn{2}{|c|}{ LATEX } & \multirow{2}{*}{$\begin{array}{c}\text { TOTAL } \\
\text { FIXAÇO DE COMPLEMENTO }\end{array}$} \\
\cline { 2 - 4 } & REAGENTE & 79 & 241 \\
\hline REAGENTE & 162 & 819 & 882 \\
\hline NÃO REAGENTE & 63 & 898 & 1123 \\
\hline
\end{tabular}

Houve concordância em 988 soros ..... $(37,98 \%)$.
Indice de Co-positividade $=0,6721$

Indice de $\mathrm{Co}$-negatividade $=0,9285$

QUADRO 5

COMPARAÇÃO ENTRE A REAÇÃO DE HEMOAGLUTTNAÇĀO E A REAÇÃO DO LATEX EM 90 SOROS

\begin{tabular}{|c|c|c|c|}
\hline \multirow{2}{*}{ HEMOAGLUTINAÇĀO } & \multicolumn{2}{|c|}{ LATTEX. } & \multirow{2}{*}{ TOTAL } \\
\hline & REAGENTE & $\begin{array}{c}\text { NÃO REA- } \\
\text { GENTE }\end{array}$ & \\
\hline REAGENTE & 39 & 15 & 54 \\
\hline DUVIDOSOS & 0 & 3 & 3 \\
\hline NÃC REAGENTE & 1 & 32 & 33 \\
\hline TOTAL & 40 & 50 & 90 \\
\hline
\end{tabular}

Houve concordância em 71 soros ..... $8,88 \%$ ).

$O$ índice de Co-positividade foi $=0,7222$ e $o$ indice de Co-negatividade $=0,9697$, indicando baixa sensibilidade e alta especificidade. 
vamente elevado de resultados falsamente negativos torna inadequado, a nosso ver, o Látex como técnica de triagem no caso de doadores em bancos de sangue. De fato, da análise do Quadro 1 resulta que os soros falsos negativos com o Látex foram 52. Traduzindo o número em porcentagem temos que $38,80 \%$ dos soros positivos à Fixação de Complemento foram negativos ao Látex. E com referência ao total dos soros consideracios no Quadro 1, o Látex proporciona $5,76 \%$ de resultados falsamente negativos.

Consicierando os dois grupos de soros procedentes de pacientes hospitalizados temos que $22,95 \%$ e $22,26 \%$ (Quadros 2 e 3 ) dos scros positivos com a Fixação de Complemento, resultaram negativos ao Látex. Com referência ao total de soros examinados em cada grupo os falsos negativos foram respectivamente $10,68 \%$ (Quadro 2) e $14,44 \%$ (Quedro 3 ).

As elevadas porcentagens de falsos negativos excluem a possibilidade do uso do Látex como método diagnóstico da infecção chagásica em pacientes hospitalizados.

Tomando como referência a Hemoaglutinação (Quadro 5), podemos ver que a porcentagem de positivos com a reação do Látex foi de $44,44 \%$ e com a reação de Hemoaglutinação de $60,0 \%$. A diferença de $15,56 \%$ é devida quase que exclusivamente aos resultados falsamente negativos proporcionados pelo Látex. De fato, de 54 soros positivos à Hemoaglutinação, só $39 \circ$ foram também ao Látex $(72,22 \%)$. A porcentagem de falsos negativos alcançou o valor de $27,78 \%$ do total de soros positivos com a Hemoaglutinação e. de $16,66 \%$ dos 90 soros examinados.

\section{CONCLUSÃO}

O antígeno Látex, comparado com a Fixação de Complemento em placa e com a Hemoaglutinação nos não parece atualmente aceitável na triagem de soros procedentes de inquéritos epidemiológicos, de doadores em bancos de sangue, e menos ainda para o diagnóstico da Doença de Chagas em pacientes hospitalizados.

A maior reserva com referência ao Látex, que emerge do nosso estudo, é a sua baixa sensibilidade, motivo pelo qual os soros falsos negativos constituem uma parcela inaceitável em qualquer trabalho de triagem.

As nossas conclusões coincidem com a opinião dos participantes do $10^{\circ}$ Simpósio Internacional Sobre a Doença de Chagas realizado em Buenos Aires em dezembro de 1972 (4).

Foram apontados também resultados nem sempre uniformes entre as várias partidas de Látex e uma estabilidade pouco satisfatória, podendo o produto deteriorar-se em períodos menores do prazo de validade (4). A sua boa especificidade todavia faz esperar que, uma vez melhorada a sensibilidade e obtida uma maior estabilidade e uniformidade de resultados entre os vários lotes, o Látex poerá constituir-se numa técnica de extrema simplicidade e praticidade na triagem sorológica da Doença de Chagas.

\section{SUMMARY}

A comparison between Complement Fixation Test and Chagas-Látex Antigen performed in:

a) 902 serum samples from an exidemiological survey;

b) 131 serum samples from hospitalized patients;

c) 90 serum samples from hospitalized patients and $r$ ?latives, showed low co-positivity index, being respectively:
a) $=0,6119$;
b) =0,7704;
c) $=0,6721$.

A comparison between Hemoaglutination Test and Chagas-Látex Antigen in 90 serum samples of c) grup showed also a low co-positivity index: 0,7222.

The authors conclude that Chagas-Látex Antigen, owing to its low sensibility rate, is hardly indicated for diagnostic purposes either in epidemiological surver areas or in hospitalized patients. 


\section{BIBLIOGRAFIA}

1. ALMEIDA, J. O. de - Reação de Fixação pela técnica quantitativa para moléstia de Chagas. Técnica em tubos e técnica em placas. In J. R. CANÇADO, "Doença de Chagas", pág. 279-314. Belo Horizonte, 1968.

2. BARACCHINI, O.; COSTA A. \& CARLONI, J. - Emprego do calor e do metanol no preparo do antígeno de Trypanosoma cruzi. Hospital, 68: 193-199,

3. BARUFFA, G. \& ALCANTARA, F. A. Comparação entre o reagente ChagasLátex e a Imunofluorescência no dıagnóstico sorológico da Doença de chagas na Zona do Rio Grande do Sul. Rev. Soc. Bras. Med. Trop. VII: 329$-332,1973$.

4. CAMARGO, M. \& SHIMIZU, S. H. Metodologia sorológica na infecção pe- lo Trypanosoma cruzi. Rev. Goiana Med. 20: 47-65, 1974.

5. KNIERIM, F.; ESKUCHE, G.; SANDOVAL, L. \& MUÑOZ, S. - Reacción de aglutinacion con Látex para el diagnóstico scrológico de enfermedad de Chagas. Bol. Chil. Faras. 26: 32-5, 1971.

6. PELLEGRINO, S. \& KATZ, M. - Comparison of the Látex slide agglutination and Complement Fixation Test for the diagnosis of Chagas'Disease. Journal Parasitology, 57: 771, 1971.

7. PRATA, A. et Al. - Etuảo sobre a prova de Látex para o diagnóstico Imunológico da Doença de Chagas. Ensaio de campo realizacio em oito centros de investigação sobre Doença de Chagas. Dados distribuídos pela Hoechst do 